\title{
Nanotechnology: A Coming Clinical Laboratory Revolution
}

\author{
LINDA L WILLIFORD PIFER, KATHLEEN KENWRIGHT
}

\begin{abstract}
ABBREVIATIONS: $\mathrm{nm}=$ nanometer; $\mathrm{IBM}=$ International Business Machines (IBM); AFM = atomic force microscope;
\end{abstract}

INDEX TERMS: nanometer, nanotechnology, nanoscale, nanotubes, fullerenes, buckyballs, atomic tweezers, atomic force microscopy, ultra-high resolution microscope, singularity, piezoelectricity, nanites, nanorobots

\section{LEARNING OBJECTIVES:}

1. Discuss the history of nanotechnology.

2. Define nanotechnology.

3. Describe the innovative nature and unique features of nanotechnology.

4. List potential applications of nanotechnology in the coming years.

Clin Lab Sci 2010;23(2);107

Linda L. Williford Pifer, Ph.D.,SM(ASCP), GS(ABB), University of Tennessee Health Science Center, Memphis, TN 38163

Kathleen Kenwright, MS, MT,MP(ASCP) SI , University of Tennessee Health Science Center, Memphis, TN 38163

Address for Correspondence: Linda L. Williford Pifer, Ph.D., SM(ASCP), GS(ABB), Professor, Clinical Laboratory Sciences, University of Tennessee Health Science Center, 930 Madison Avenue, Suite 672, Memphis, TN, 38163, 901-448-6338., lpifer@uthsc. edu

"My own judgment is that the nanotechnology revolution has the potential to change America on a scale equal to, if not greater than, the computer revolution." U.S. Senator Ron Wyden (D-Oregon). ${ }^{1}$
It is imperative that all generations of clinical laboratory scientists understand and appreciate the enormous potential for nanotechnology to solve problems and to improve the quality of our lives and of those receiving medical treatment. These include, but are not limited to, diagnosis, treatment and management of many conditions. Unique insight may be gained into infections, malignancies, genetic errors and enhanced, targeted drug-delivery systems. Nanotechnology is already revolutionizing communications, materials engineering, energy production and approaches to environmental issues. This is a "must know" technology and we need to understand how it will apply to lifechanging advances in the clinical laboratory.

Nanoscale refers to matter that occupies space equal to one to ten billionths of a meter (one billionth of a meter $=1$ nanometer, Table 1). A red blood cell averages 7000 nanometers $(\mathrm{nm})$, and a human hair measures approximately $50,000 \mathrm{~nm}$ in diameter. ${ }^{2}$

Table 1. Examples measured on a nanoscale. ${ }^{2}$

\begin{tabular}{ccc}
\hline $\begin{array}{c}\text { DNA 2.5 nm } \\
\text { diameter }\end{array}$ & Bacterium 25,000 & Large rain drop \\
nm Long & $25,000,000 \mathrm{~nm}$ \\
$\begin{array}{c}\text { Single-walled } \\
\text { Nanotube }\end{array}$ & $\begin{array}{c}\text { Strand of human hair } \\
\text { nm diameter }\end{array}$ & $\begin{array}{c}\text { Width of a } \\
\text { house }\end{array}$ \\
$\begin{array}{c}\text { Nanoparticle } 4 \\
\text { nm long }\end{array}$ & $100,000 \mathrm{~nm}$ & $10,000,000,000 \mathrm{~nm}$ \\
& $4,000,000 \mathrm{~nm}$ & $400,000,000,000 \mathrm{~nm}$ \\
\hline
\end{tabular}

One nanometer is approximately equivalent to the diameter of three or four atoms. ${ }^{1}$ Nanotechnology is defined by the National Science and Technology Council (NSTC), as research in the range of 1-100 nm. ${ }^{3}$ One might say that the "nanoworld" lies in the 


\section{FOCUS: NANOTECHNOLOGY}

"depths of inner space," where the properties of matter are no longer what we have been taught. Tensile strength, chemical bonds, and magnetism display uncommon properties. An example would be the enormous strength of spider web silk. Nanocrystals responsible for this strength have conveyed the same property upon nanosteel, which surpasses carbon steel in this all important structural quality. ${ }^{4}$ Nanostructures are present in soot and cause the iridescence in butterfly wings (Figure 1).

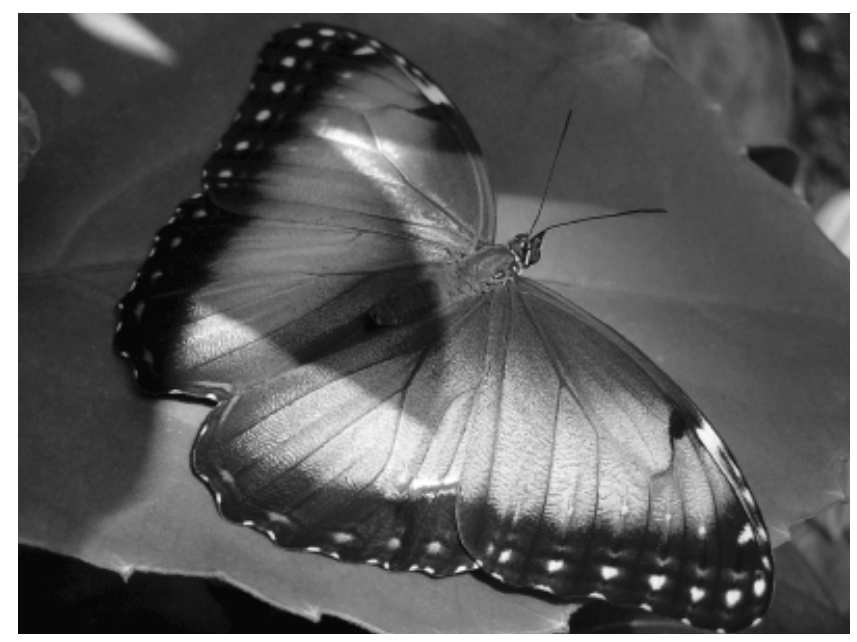

Figure 1. Butterfly with iridescent wings.

\section{History}

In 1959, in his now famous lecture, "There is Plenty of Room at the Bottom", Dr. R. Feynman was among the first to conceive the idea that atoms could be manipulated. ${ }^{5}$ K. Eric Drexler's 1981 paper, "Molecular engineering: an approach to the development of general capabilities for molecular manipulation", ${ }^{6}$ established the basis for "molecular engineering and nanosystems that could potentially produce them". O Osawa (Toyohashi University of Technology) forecast the possibility of producing three-dimensional sixty-carbon $\left(\mathrm{C}_{60}\right)$ structures shaped like soccer balls and, indeed, they were first prepared in 1991 (Figure 2). ${ }^{8}$

Almost 25 years earlier in another discipline (architecture), the famous and innovative Buckminster Fuller, a noted scientific thinker and futurist, designed the Montreal geodesic dome (U.S. pavilion at Expo 67). These geodesic domes created by Fuller have basically the same proportions as the $\mathrm{C}_{60}$, thus the basic sixty- carbon soccer ball-shaped structures were termed "fullerenes" or "buckyballs", in honor of Dr.Fuller."

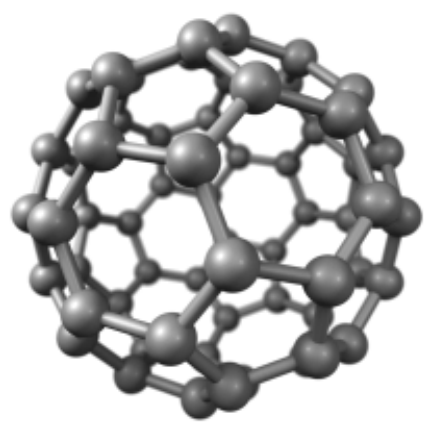

Figure 2. Sixty carbon structure.

In 1996, Kroto, Curl and Smalley received the Nobel Prize in Chemistry for their contribution to the discovery of this phenomenal class of compounds which, with additional atoms and manipulation, can be formed into single, double, triple, etc. nanotubular structures. $^{10-12}$ These structures, or nanotubes of graphene (an allotrope of carbon), resemble a roll of chicken wire, except instead of being made of metal, nanotubes are composed of carbon atoms in a hexagonal lattice formation (Figure 3). ${ }^{13}$ Nanotubes range in size from 0.4 nanometers in diameter to the millimeter range, produced by Nanocomp Technologies, Inc. ${ }^{15}$ Nanocomp has found a method to produce longer nanotubes that are lighter than aluminum, 100

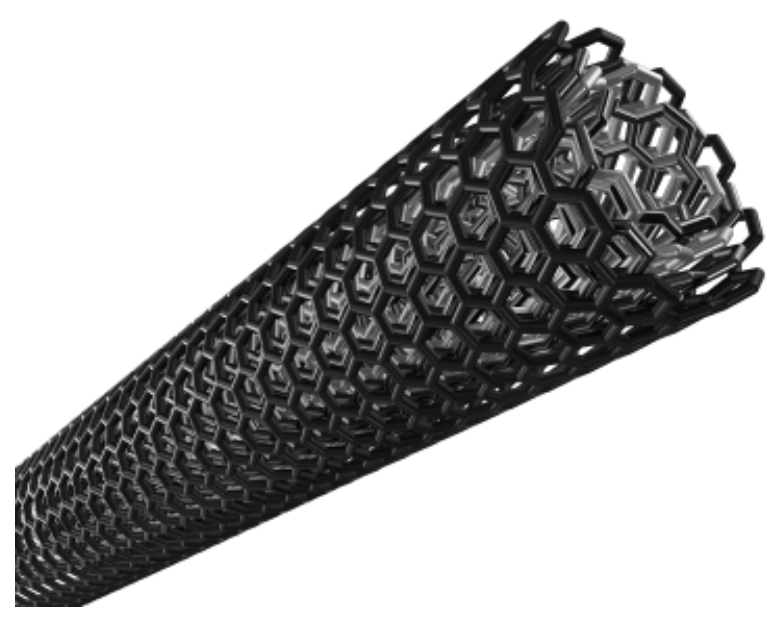

Figure 3. Nanotubular Structure 


\section{FOCUS: NANOTECHNOLOGY}

times stronger than steel, have the ability to conduct electricity and transfer heat. "It would take an elephant, balanced on a pencil, to break through a sheet of grapheme the thickness of Saran-Wrap ${ }^{\oplus 1}{ }^{16}$

The applications for products with these properties seem endless. Nanocomp Technologies has joined with the United States Army Natick Soldier Center and the United States Navy Office of Naval Research to improve body armor and develop interference shields for the military. ${ }^{13,15}$

\section{Scientific Principles of Nanotechnology}

Tiny carbon, silicon or silicon nitride nanotubes used as a tip in the atomic force (scanning-tunneling) microscope make it possible to penetrate samples that are only a few nm deep. ${ }^{16}$ With the aid of the atomic force microscope (AFM), whose resolution is approximately one thousand-fold superior to that of optical diffraction microscopes, we can at last "see" a single atom. To demonstrate, in the mid 1990s, International Business Machines (IBM) produced the world's smallest company logo using 35 xenon atoms, which were individually picked up and placed in the desired order. ${ }^{17,18}$

To understand how this is possible, a brief sojourn into the world of piezoelectricity is necessary. It involves the phenomenon of single atom manipulation. When placed end-to-end, crystals of high purity, when tapped, will produce a flow of electrons known as a piezoelectric current. $^{19}$ This and other physicochemical forces (magnetism, Van der Waal's forces, manipulation of ordinary chemical bonds) enable the probe tip of the AFM, to apply "tweezers" (twin laser beams) to position single atoms in a chilled cesium cloud. The twin lasers ("prongs" of the tweezers) create a "standing wave" series of peaks and troughs that pulse atoms along a beam to the desired destination. Single atoms are shifted three-dimensionally, one-by-one, into position. ${ }^{18}$ This is made possible by a "cantilever" arm, usually made of silicon or silicon nitride nanotubes that are stationary at one end and are capable of being diverted or "focused" at an atomic level by piezoelectric forces and other previously described phenomena.

To better visualize this, one can think of a phonograph in which the "arm" bearing the needle makes contact with the record grooves to produce music. In the AFM, the "needle" is the tiny carbon (or other material) nanotubular probe, and the "arm" is the cantilever, which dips up and down at the will of the operator. ${ }^{21}$ The technician can observe the highly magnified and enhanced field of focus, and can literally see atoms being picked up and repositioned on a television-like monitor.

Another advance that will boost our knowledge of nanotechnology is the new ultra-high resolution microscope, whose development is currently in progress in Germany. It will have a resolution of fifty-billionths of a millimeter, the capability of measuring atomic distances and will assist in studying chemical bonding. ${ }^{22}$

These are indeed impressive accomplishments, but how will these advances translate into diagnostic capabilities in the clinical laboratory? Already, cantilever arms (minute movable platforms) bearing multiple antibodies or other reactive components are being developed for use in the clinical laboratory, in environmental monitoring and in a myriad of other innovative venues. These cantilevered projections coated with specific antibody physically "dip" or bend, which results in changes in resonant frequency when brought into proximity with corresponding pathogens or other targets. The signals are specific and can be detected with high sensitivity and accuracy, permitting identification (quantitatively) of bacteria, viruses, illicit drugs, toxins and contaminated food and water, to name only a few. ${ }^{18}$

\section{Revolutionary Nature of Nanotechnology}

Nanotechnology unquestionably qualifies as a technological singularity. It produces events that occur during unprecedented technological progress and lead to an intelligence explosion and rapid growth of new and better ways of accomplishing goals. ${ }^{20}$ Technological singularities change human life and its quality. Nanotechnology, the newest singularity, represents engineering on the atomic level, and will enable us to construct things "from the bottom up" ${ }^{2}$ rather than merely reformatting or amplifying existing chemical groups, molecules and materials. We will no longer need to depend exclusively upon traditional chemical reactions to produce materials. It is now possible to 


\section{FOCUS: NANOTECHNOLOGY}

individually shift single atoms into position for the purpose of preconceived and predicted bonding in order that specific platforms might be created for diagnostic and other purposes. Nanotechnology will likely spearhead advances that will forestall starvation of the world's burgeoning population and effectively deal with the need for an abundance of energy that can be produced cheaply and cleanly.

The advent of self-replicating machines is at hand. Nanomachines (nanites) are mechanical or electromechanical devices that operate in the nanometer range. Although they are still in development, some relatively simple devices have been tested. A sensor has been developed with a switch that is $1.5 \mathrm{~nm}$ in diameter, and is capable of enumerating specific molecules in an analyte-containing specimen. The most immediate use of nanites will likely be in the clinical laboratory in the detection of diagnostic molecules, pathogens and toxins in patient specimens. Self-replicating nanites (nanorobots) could be designed to construct larger devices. Specialized nanites might be designed to "search and destroy" microbial invaders and others could be designed precisely for delivering drugs to targeted tissues Many of these clinical/technical applications will be detailed in Part 2 of this issue, while Parts 3 and 4 will address environmental, societal and safety concerns.

Other singularities or technological "supernovas" have included the agricultural, industrial, chemical, atomic and molecular biology revolutions. The dawning of nanotechnology is no less bright than these, and its value in advancing clinical laboratory diagnosis, science and human health is on the verge of becoming manifest. Splitting the atom was a phenomenal event, but constructing devices one atom at a time, and making such devices self-replicating, will potentially prove to be the closest approach yet to the Holy Grail of technology.

\section{REFERENCES}

1. Wyden R. What is nanotechnology? Center for Responsible Nanotechnology c 2002-2008 Available from: http://www. crnano.org/whatis.htm. [cited Sept 19, 2009].

2. Nanotechnology: Big Things from a Tiny World. National Nanotechnology Coordination Office, Arlington: Available from http://www.nano.gov/Nanotechnology_BigThingsfroma
TinyWorldspread.pdf. [cited Sept 15, 2009].

3. Burtis CA, Ashwood ER, Bruns DE. Nanotechnology and microfabrication. In Tietz N, Textbook of Clinical Chemistry and Molecular Diagnostics, 4th ed. St. Louis: Elsevier; 2006. p. 245.

4. Timmer J. Scientists mix in metal to make super-strength spider silk. Science 2009 April 23; doi: 10.1126/science. 1168162. Available from: http://www.arstechnica.com/science/ news/2009/04/metal-enhanced-spider-silk-tougher-than-theoriginal.ars [cited Sept 15, 2009].

5. Phoenix C. Nanotechnology press kit--history of nanotechnology. Nanotechnology Now 2009. Available from: http://www.nanotech-now.com/Press_Kit/nanotechnologyhistory.htm. [cited April 23, 2009]

6. Drexler KE. Molecular engineering: an approach to the development of capabilities for molecular manipulation. Proc Natl Acad Sci USA 1981; 78-81. Available from: http://www.pnas.org/content/78/9/5275.full.pdf+html. [cited Sept 22, 2009]

7. E-drexler.com. Drexler KE. Available from:http://edrexler.com/p/idx04/00/0404drexlerBioCV.html. [cited Sept 22, 2009].

8. Boyd DB, Slanina Z. Introduction and foreword to the special issue commemorating the thirtieth anniversary of Eiji Osawa's C60 paper. J Molecular Graphics Modeling 2001 April; doi: 10.1016/S1093-3263(00)00106-6.

9. Hoffman $\mathrm{RD}$. The potential impact and importance of $\mathrm{R}$ Buckminster Fuller's vision of a global energy grid. Spring. Available from http://www.animatedsoftware.com/geni/rh2000 ge.htm.

10. Curl RF. $\mathrm{C}_{60}$ Yesterday and Today. [newsletter]. Chem NZ 1992;47:3-14.

11. Kroto HW. Semblable molecules in the laboratory and space. Chem Soc Rev 1982;11:435-91.

12. Smalley RE. Great balls o'carbon. The Sciences 1991;31:22 8.

13. Cass S. Forget nanotubes-here come nanosheets. Discover 2009; July: 22.

14. Wong K. The tiniest carbon nanotubes. Sci American 2000 Nov 6. Available from http://www.scientificamerican.com/ article.cfm?id=the-tiniest-carbon-nanotu [cited Sep 20, 2009].

15. Nanocomp Technologies, Inc Available from:http://www.nano comptech.com/html/nanocomp-what-we-do.html. [cited Sept 20, 2009]

16. Cise.columbia.edu. Columbia University Center for Integrated Science \& Engineering; Nanoscale science and engineering center. 2001-9 [updated 2009 Oct22; cited 2009 Nov 8].

17. Columbia engineers confirm graphene as strongest material. Available from http://www.cise.columbia.edu/nsec/news/

18. Alivisatos PA. Less is more in medicine. In Understanding Nanotechnology. Scientific American, editors. New York: Time Warner Book Group; 2002 p. 65.

19. Blanchard CR. Atomic force microscopy. The Chemical Educator. 1996;1:1-8.

20. IBM researchers demonstrate new method for rapid molecule sorting and delivery. IBM Research Press Resources 2006; May 1. Available from http://domino.watson.ibm.com/comm/pr.nsf/ 


\section{FOCUS: NANOTECHNOLOGY}

pages/news.20060501_afm.html [cited Nov 7, 2009].

21. Microscopy AFMSP. The Atomic Force Microscopy Resource Library. Agilent Technologies, Inc. Available from: http:// www.afmuniversity.org/index.cgi?CONTENT_ID=33 [cited 2009 Nov 9].

22. Morton T. Measuring the strength of individual graphene sheets. Science 2008. doi:10.1126/science. 1157966. Available from http://arstechnica.com/science/news/2008/07/measuringthe-strength-of-individual- graphene-sheets.ars [cited Nov 9, 2009].

23. Nanotechnologydevelopmentblog.com. World's ultra-high re- solution microscope's working is in progress. Available from: http://www.nanotechnologydevelopment.com [cited Nov 8, 2009]

24. Phoenix C. Science, nanotechnology, and responsibility. NanoNews Diges; 2002 Oct. Available from: http://www. nanotech-now.com/Chris-Phoenix/science-nanotechnologyresponsibility.htm [cited Nov 8, 2009].

25. What is.com Target Search ${ }^{\mathrm{TM}}$ Available from http://whatis.tech target.com/definition/0,,sid9_gci514355,00.html [cited Nov 8, 2009].

The Focus section seeks to publish relevant and timely continuing education for clinical laboratory practitioners. Section editors, topics, and authors are selected in advance to cover current areas of interest in each discipline. Readers can obtain continuing education credit (CE) through P.A.C.E. by completing the continuing education registration form, recording answers to the examination, and mailing a photocopy of it with the appropriate fee to the address designated on the form. Suggestions for future Focus topics and authors, and manuscripts appropriate for CE credit are encouraged. Direct all inquiries to the Clin Lab Sci Editorial Office, Westminster Publishers, 315 Westminster Court, Brandon MS 39047. (601) 214-5028,(202) 315-5843 (fax).westminsterpublishers@comcast.net. 